\title{
Guanine Nucleotide-Binding Protein G(i) Subunit Alpha-1
}

National Cancer Institute

\section{Source}

National Cancer Institute. Guanine Nucleotide-Binding Protein G(i) Subunit Alpha-1. NCI

Thesaurus. Code C38380.

Guanine nucleotide-binding protein G(i) subunit alpha-1 (354 aa, $\sim 40 \mathrm{kDa}$ ) is encoded by the human GNAl1 gene. This protein may play a role in signal transduction by inhibiting adenylate cyclase in response to beta-adrenergic stimuli. 